\title{
Inpatient rehabilitation outcomes in solid organ transplantation: Results of a unique partnership between the rehabilitation hospital and the multi-organ transplant unit in an acute hospital
}

\author{
John T. Patcai ${ }^{1,2,3^{*}}$, Marie P. Disotto-Monastero ${ }^{3}$, Manuel Gomez ${ }^{1,3}$, \\ Lesley E. Adcock ${ }^{1,2}$ \\ ${ }^{1}$ Faculty of Medicine, University of Toronto, Toronto, Canada; ${ }^{*}$ Corresponding Author: djpatcai@gmail.com \\ ${ }^{2}$ University Health Network (UHN), Toronto General Hospital, Toronto, Canada \\ ${ }^{3}$ Sunnybrook Health Sciences Centre, Toronto, Canada
}

Received 30 July 2013; revised 1 September 2013; accepted 10 September 2013

Copyright (C) 2013 John T. Patcai et al. This is an open access article distributed under the Creative Commons Attribution License, which permits unrestricted use, distribution, and reproduction in any medium, provided the original work is properly cited.

\begin{abstract}
Objective: To determine the outcomes in solid organ transplant recipients following inpatient rehabilitation, as a result of a unique partnership between the rehabilitation hospital and the multiorgan transplant program in an acute hospital. Design: Retrospective observational study. Setting: Community rehabilitation hospital affiliated with a university. Participants: A cohort of $\mathbf{1 7 3}$ organ transplant patients admitted consecutively over a four-year period (2004-2008) was compared to a cohort of all rehabilitation patients ( $n$ = 9762) admitted to the same inpatient rehab facility during the same period. Interventions: Inpatient rehab program to all participants. Main Outcome Measures: Length of hospital stay, Functional Independence Measure (FIM ${ }^{\mathrm{TM}}$ ) change (admission-discharge), and rate of discharges to home. Results: Outcomes were measured using components of the $\mathrm{FIM}^{\mathrm{TM}}$ instrument, admission and discharge data. Chi-square and independent two-sample $t$-tests were used for statistical analysis. Compared to a general rehabilitation inpatient population, transplant rehabilitation inpatients had: more immediate ( $<3$ days) transfers to an acute hospital ( $5.2 \%$ vs. $1.9 \%, p<$ 0.001 ); a higher rate of readmission to an acute hospital after the first 3 days $(19.1 \%$ vs. $1.9 \%, p<$ $0.001)$; a longer mean length of stay ( $27 \pm 19$ vs. $20 \pm 18$ days, $p<0.001$ ); a lower total FIM $^{\mathrm{TM}}$ change (8.9 vs. 20.9, $p<0.001$ ); a lower FIM $^{\mathrm{TM}}$ efficiency (1.1 vs. 1.4, $p<0.001$ ); and a higher rate of dis-
\end{abstract}

charges to home in patients not readmitted to acute care $(98.5 \%$ vs. $94.5 \% p<0.001)$. Conclusion: Outcomes of rehabilitation in solid organ transplant patients are comparable but not identical to those in other patient groups. Inpatient rehabilitation for transplant patients is therefore fully justifiable and necessary. The ten times higher rate of transplant patient readmission to acute hospital must be communicated, facilitated, accepted and managed within a partnership strategy.

Keywords: Rehabilitation; Outcomes Assessment; Transplants; Patient Readmission; Health Planning Guidelines

\section{INTRODUCTION}

Different studies have shown some effects of transplantation on quality of life (QoL). QoL improves post liver transplant [1], primarily in areas affected by physical functioning with improvement in psychological function. QoL also may improve after renal transplant [2,3], pancreas-kidney transplant [4,5], heart and heart-lung transplant [6], heart, liver and lung transplant [7], and post solid organ (liver, heart, kidney and lung) transplant [8]. It is not known how much of the improvement in QoL is attributable to any rehabilitation process.

The literature provides some indications that physical function can be improved in transplantation with rehabilitation treatment. It is possible to find some data on outpatient rehabilitation post-transplant. Physical performance can be improved on an outpatient basis post 
liver transplant [9], lung transplant [10], kidney transplant $[11,12]$, pancreas-kidney [13] transplant and cardiac transplant [14-18].

On an inpatient basis, there are little data. There is, for instance, a report of a single case of complicated inpatient rehabilitation post liver transplant [19]. Providing occupational therapy services post-transplant in an acute hospital is effective in improving function [20]. The largest study of inpatient rehabilitation published to date reported on 55 patients [21], all of whom were liver transplants. They noted significant functional gains, but warned of complications. Another study [22] of twelve patients, reported on inpatient rehabilitation stays post cardiac rehab, with improvements in their degree of independence measured by the Barthel Activities of Daily Living index. A study of inpatient rehabilitation [23] of 45 patients with end-stage renal disease (ESRD) concluded that "ESRD patients on hemodialysis had similar FIM $^{\mathrm{TM}}$ scores to patients with renal transplantation", and "In particular, ESRD patients with stroke achieved lower motor and cognitive FIM $^{\mathrm{TM}}$ scores than other ESRD patients and made fewer gains in motor FIM $^{\mathrm{TM}}$ scores than stroke patients without ESRD".

Organ transplant patients develop a number of impairments during the pre-transplant, and peri-transplant phases. Most patients are much deconditioned [24], and some may be nutritionally depleted [25], anaemic, in respiratory or in cardiac failure. They are likely to suffer some of the complications of bed rest [26,27]. Complications such as neuropathy and myopathy are associated with ICU stays in general [28-31], and specifically in liver transplants [32-34]. Uremic patients [35] may have myopathies, and many patients may be taking some medications such as colchicine or cyclosporine [36]. Cognitive impairments may occur on the basis of the disease (e.g. organ failure such as liver [37], heart or lung [38]), treatment with some medications (even less toxic medications such as corticosteroids [39]), or as a complication of cardio-pulmonary by-pass (at least during coronary artery by-pass grafting [40]). Cognitive impairments from liver disease may improve post-transplant [34].

Impairments such as those listed are in fact routinely treated in the inpatient rehabilitation setting in other patient groups. This raises the question of whether inpatient rehabilitation can improve physical function in the posttransplant group.

A rehabilitation program was established by a Rehab Hospital (RH) in partnership with a Multi-Organ Transplant (MOT) program in an acute hospital. A formal, written partnership was created between the $\mathrm{RH}$ and the MOT. The RH was the provider of choice for MOT patients requiring inpatient rehabilitation. Up to six rehab beds could be available for these patients. The RH had clear admission criteria and processed admission re- quests rapidly in order to clear the MOT beds expeditiously. Original diagnosis and type of transplanted solid organ were not considerations. The only real consideration was whether the patient had goals that could be achieved in an inpatient rehab program. The MOT provided medical support by offering education sessions to medical and pharmacy staff, and day to day support via telephone, pager, follow-up clinics and by telehealth. Both partners worked to convince the ambulance services to repatriate acutely ill patients from the $\mathrm{RH}$ directly to the MOT, when otherwise their policy was to take patients to the nearest emergency department. The MOT ensured that beds and/or resources would be available for repatriation if needed.

The purpose of this study was to report the outcomes of 173 post solid organ transplant patients who came to the inpatient rehab program, and reviewed the features of the unique partnership (RH-MOT) which allowed it to succeed.

\section{METHODS}

This was a retrospective observational cohort study of all solid organ transplant patients from the MOT $(\mathrm{n}=$ 173) consecutively admitted to the RH in the first four fiscal years after the creation of the partnership (April 1, 2004 to March 31, 2008). The control cohort was the entire patient population admitted to the $\mathrm{RH}$ during this same time period $(n=9762)$. The RH had eight inpatient rehab programs - amputee, burn, cardiac, musculoskeletal, neurological, oncological, transplant, and trauma. Over half of the entire population of the RH consisted of postoperative orthopaedic patients, mostly total joint arthroplasties. No patients were excluded from the study.

\section{Specific Rehabilitation Program for Organ Transplant Patients}

There were no specific components of the rehabilitation program usually adjusted by patient diagnosis, or by type of organ transplanted. Nor in fact was the disease that caused the need for transplant considered unless the disease caused specific changes in Body Functions, Structure, Activities or Participation that required rehabilitation considerations. Each rehabilitation program was specifically tailored to the individual patient with their individual list of problems with Body Functions, Structure, Activities and Participation as identified by the patient and the rehabilitation team, in the context of which abilities were most needed by the patient. As noted in the introduction above, the most common problems were extreme fatigue, severe deconditioning, nutritional depletion, metabolic toxicity, myopathy, neuropathy, cognitive loss secondary to disease or its treatment, and depression. In fact, this list is more a list of problems 
of long standing, chronic, and severe illness than a list of problems with specific organs or specific diseases. As such, the rehabilitation program for the transplant patients had much in common with many of the other programs at the RH. The problems experienced by transplant program patients compared to those in the cardiac, severe trauma, severe medical illness, burn, and oncology programs usually had many more similarities than differences.

Medical complications included rejection of the transplanted organ, anemia, cardiac failure, respiratory failure and infections. Medical complications were sometimes treated in the RH, but more often in the MOT.

The electronic data collected was part of the routine operation of the RH. Basic demographic information, admission and discharge information, including the Functional Independence Measure $\left(\mathrm{FIM}^{\mathrm{TM}}\right)$ are routinely collected and entered into the RH electronic database.

The FIM $^{\mathrm{TM}}$ instrument was developed in 1983 by a national task force in the United States to meet a long standing need for an outcome measure that documents the severity of patient disability and outcomes of medical rehabilitation [41]. The FIM $^{\mathrm{TM}}$ instrument is the most widely used standardized functional outcome measure in medical rehabilitation. The $\mathrm{FIM}^{\mathrm{TM}}$ instrument has been recognized as an indicator of burden of care and has the ability to predict the need for rehabilitation services [42-46]. The FIM ${ }^{\mathrm{TM}}$ instrument consists of 18 items with 2 subscales: motor (13 items) and cognitive (5 items). Each item is given a rating of $1-7$, the lower the rating the more dependent, the higher the rating the more independent. The ratings are tallied up for a maximum total rating of 126 and a minimum rating of 18 [47].

The FIM $^{\mathrm{TM}}$ instrument has demonstrated reliability and validity in a number of different patient populations (multiple sclerosis, stroke $[43,45,48-50]$, spinal cord injury $[42,51,52]$, traumatic brain injury $[42,46]$, and in the burn population) [53-55], as a general measure of functional independence [56]. The $\mathrm{FIM}^{\mathrm{TM}}$ gain is the difference between the discharge and admission FIM $^{\mathrm{TM}}$ scores and higher values indicate greater functional independence during hospitalization. The $\mathrm{FIM}^{\mathrm{TM}}$ efficiency is the $\mathrm{FIM}^{\mathrm{TM}}$ gain divided by the length of stay, and measures rate of functional improvement [57].

All planned discharges have a discharge FIM $^{\mathrm{TM}}$ rating on file. Planned discharges occur when all established goals are completed - either achieved or abandoned. Discharge FIM $^{\mathrm{TM}}$ rating is not measured if the rehab program is interrupted (i.e. an unplanned discharge). For reasons of mandated reporting, unplanned discharges are separated into discharges soon after admission $(<3$ days $)$ and discharges after 3 days.

The RH Research Ethics Board approved the research protocol. The data was retrospectively analyzed for the two described cohorts. The outcomes of the organ transplant group were compared by fiscal year $(2004,2005$, $2006,2007,2008)$ to determine if there were differences overtime. Chi-square and one sample $t$-tests were used for statistical analysis, with a $\mathrm{p}<0.05$ considered significant.

\section{RESULTS}

Table 1 shows the demographics of the 173 organ transplant patients who underwent inpatient rehabilitation. The majority were men (56.6\%), post liver (43.4\%), followed by lung $(24.9 \%)$, and organ transplants with more than 1 year post transplant $(16.8 \%)$. Compared to the general rehabilitation population, transplant patients were more likely to be male $(56.6 \%$ vs. $36.0 \%$, p $<0.001)$ and younger (54.9 vs. 69.5 years, $\mathrm{p}<0.001)$. Unplanned discharges soon after admission (transfers to acute care MOT within three days of rehab admission) were more likely to occur in transplants than the general rehabilitation population ( $5.2 \%$ vs. $1.9 \%, \mathrm{p}<0.002)$. Readmission to an acute care facility after the first 3 days was greater for the transplant population $(19.1 \%$ vs. $1.9 \%, \mathrm{p}<0.001)$. Transplant patients had longer mean length of stay $(27 \pm$ 19 vs. $20 \pm 18$ days, $p<0.001$ ) and slightly lower FIM $^{\text {TM }}$ efficiency scores $(1.1$ vs. $1.4, \mathrm{p}<0.001)$ than did the general rehabilitation population. Mean motor (13.1 vs. $20.4)$, cognitive ( -4.9 vs. 0.5$)$ and total FIM $^{\mathrm{TM}}$ (8.9 vs. 20.9) rating changes were significantly lower in the transplant population than the general rehabilitation population (Table 2).

Of the transplant patients who were not readmitted to

Table 1. Demographics of transplant patients.

\begin{tabular}{cc}
\hline Patients & 173 \\
\hline Age (Years) & $54.9 \pm 12.0$ (range 18 - 83) \\
Gender & $98(56.6)$ \\
Males (\%) & $75(43.4)$ \\
Females (\%) & \\
Organ Transplant Groups & $75(43.4)$ \\
Liver (\%) & $43(24.9)$ \\
Lung (\%) & $10(5.8)$ \\
Heart (\%) & $3(1.7)$ \\
Heart-Lung (\%) & $3(1.7)$ \\
Kidney (\%) & $10(5.8)$ \\
Combined (\%) & $29(16.8)$ \\
\hline
\end{tabular}

Combined $=$ several organs transplanted in the same operation; Old transplants $=$ with more than 1 year post-transplant. 
an acute care hospital, $98.5 \%$ were able to successfully meet their rehabilitation goals and were discharged home directly from the $\mathrm{RH}$, compared to $94.5 \%(\mathrm{p}<0.001)$ of the general rehab patients (Table 2).

\subsection{Outcomes by Organ Transplant Group}

Patients post-kidney transplant were significantly older (64 years), patients post-combined transplants (who had several organs transplanted in the same operation) had more immediate ( $<3$ days) transfers to an acute hospital $(10 \%)$, and a higher rate of readmission to an acute hospital after the first 3 days (20\%), and patients who received a heart-lung transplant had greater FIM $^{\mathrm{TM}}$ efficiency (1.2) than the other organ transplant groups (Table 3).

\subsection{Outcomes of Organ Transplant Group by Year}

The greater improvements in outcomes were seen in last two years of the study. In 2007, there were more transplant patients admitted to the RH $(61 \%, 35.3 \%)$. and there was a significantly reduced waiting time for $\mathrm{RH}$ admission (1.6 days). In 2008, there were no immediate ( $<3$ days) transfers to an acute hospital, no readmission to an acute hospital after the first 3 days, and all patients met the rehab goals and were discharged to their homes (Table 4).
Table 2. Demographics and outcomes by patient groups.

\begin{tabular}{cccc}
\hline & Transplant & All Rehab & p Value \\
\hline Patients (\%) & $173(1.7)$ & $9762(98.3)$ & $<0.001$ \\
Age (Years) & $54.9 \pm 12.0$ & $69.5 \pm 13.1$ & $<0.001$ \\
Gender & & & \\
Males (\%) & $98(56.6)$ & $3514(36.0)$ & $<0.001$ \\
Females (\%) & $75(43.4)$ & $6248(64.0)$ & $<0.001$ \\
Unplanned Discharges (\%) & $9(5.2)$ & $189(1.9)$ & $<0.002$ \\
Acute Care Readmissions (\%) & $33(19.1)$ & $185(1.9)$ & $<0.001$ \\
LOS (Days \pm SD) & $27.1 \pm 19.2$ & $20.3 \pm 18.2$ & $<0.001$ \\
Motor FIM ${ }^{\mathrm{TM}}$ Gain ( \pm SD) & $13.1 \pm 31.5$ & $20.4 \pm 9.3$ & $<0.001$ \\
Cognitive FIM ${ }^{\mathrm{TM}}$ Gain ( \pm SD) & $-4.9 \pm 12.9$ & $0.5 \pm 9.8$ & $<0.001$ \\
Total FIM ${ }^{\mathrm{TM}}$ Gain ( \pm SD) & $8.9 \pm 43.4$ & $20.9 \pm 9.8$ & $<0.001$ \\
FIM $^{\mathrm{TM}}$ Efficiency (Points/Day \pm SD) & $1.1 \pm 0.6$ & $1.4 \pm 0.9$ & $<0.001$ \\
Met Rehab Goals (\%) & $129(74.6)$ & $9225(94.5)$ & $<0.001$ \\
Discharged Home (\%) & $129(74.6)$ & $9225(94.5)$ & $<0.001$ \\
Discharged Home 2 (\%) & $129(98.5)$ & $9225(94.5)$ & $<0.001$ \\
\hline
\end{tabular}

*Chi-square test or Student's $t$-test between Transplant and All Rehab values; Unplanned Discharges $=$ inpatient stay that lasts 3 days or less, including the admission day; $\operatorname{LOS}=$ length of stay; FIM $=$ functional independence measure; FIM gain = difference between discharge FIM and admission FIM scores; FIM efficiency = FIM gain divided by the length of stay; Discharged Home 2 = in patients not readmitted to acute care $(n=131)$.

Table 3. Demographics and outcomes by organ transplant group.

\begin{tabular}{ccccccccc}
\hline & Liver & Lung & Heart & Heart-Lung & Kidney & Combined Old Transplants p Value $^{*}$ \\
\hline Patients (\%) & $75(43.3)$ & $43(24.9)$ & $10(5.8)$ & $3(1.7)$ & $3(1.7)$ & $10(5.8)$ & $29(16.8)$ & $0.001^{b}$ \\
Age (Years) & $54.6 \pm 10.3$ & $53.6 \pm 11.9$ & $49.8 \pm 9.8$ & $44.0 \pm 19.2$ & $64.0 \pm 6.6$ & $50.8 \pm 12.0$ & $60.6 \pm 14.6$ & $0.024^{a}$ \\
Gender & & & & & & & \\
Males (\%) & $41(54.7)$ & $23(53.5)$ & $7(70.0)$ & $1(33.3)$ & $2(66.7)$ & $4(40.0)$ & $20(69.0)$ & 0.579 \\
Females (\%) & $34(45.3)$ & $20(46.5)$ & $3(30.0)$ & $2(66.7)$ & $1(33.3)$ & $6(60.0)$ & $9(31.0)$ & 0.579 \\
Unplanned Discharges (\%) & $6(8.0)$ & $0(0.0)$ & $0(0.0)$ & $0(0.0)$ & $0(0.0)$ & $1(10.0)$ & $2(6.9)$ & $0.006^{b}$ \\
Acute Care Readmission (\%) & $0(0.0)$ & $0(0.0)$ & $0(0.0)$ & $0(0.0)$ & $0(0.0)$ & $2(20.0)$ & $1(3.4)$ & $0.006^{b}$ \\
LOS (Days \pm SD) & $25.7 \pm 18.2$ & $32.3 \pm 21.1$ & $23.4 \pm 21.8$ & $18.7 \pm 8.5$ & $26.7 \pm 10.6$ & $17.6 \pm 10.1$ & $28.8 \pm 20.0$ & 0.308 \\
Motor FIM ${ }^{\mathrm{TM}}$ Gain ( \pm SD) & $9.8 \pm 34.6$ & $23.4 \pm 23.5$ & $-4.4 \pm 44.5$ & $23.3 \pm 17.6$ & $19.7 \pm 6.7$ & $1.3 \pm 38.4$ & $13.6 \pm 25.1$ & 0.114 \\
Cognitive FIM ${ }^{\mathrm{TM}}$ Gain ( $\left.\pm \mathrm{SD}\right)$ & $-5.6 \pm 14.6$ & $-2.4 \pm 9.7$ & $-11.8 \pm 15.8$ & $0.7 \pm 1.2$ & $0.3 \pm 0.6$ & $-9.9 \pm 16.6$ & $-4.1 \pm 11.0$ & 0.306 \\
Total FIM ${ }^{\mathrm{TM}}$ Gain ( \pm SD) & $4.2 \pm 47.8$ & $21.0 \pm 32.2$ & $-16.0 \pm 60.0$ & $24.0 \pm 18.7$ & $20.0 \pm 7.0$ & $-8.6 \pm 54.7$ & $9.5 \pm 35.4$ & 0.145 \\
FIM $^{\mathrm{TM}}$ Efficiency (Points/Day $\left.\pm \mathrm{SD}\right)$ & $-0.8 \pm 4.4$ & $0.8 \pm 1.7$ & $-3.9 \pm 7.3$ & $1.2 \pm 0.5$ & $0.9 \pm 0.5$ & $-2.3 \pm 7.0$ & $-0.1 \pm 2.4$ & $0.018^{a}$ \\
Met Rehab Goals (\%) & $50(66.7)$ & $38(88.4)$ & $6(60.0)$ & $3(100.0)$ & $3(100.0)$ & $6(60.0)$ & $23(79.3)$ & 0.076 \\
Discharge Home (\%) & $50(66.7)$ & $38(88.4)$ & $6(60.0)$ & $3(100.0)$ & $3(100.0)$ & $6(60.0)$ & $23(79.3)$ & 0.076 \\
\hline
\end{tabular}

Combined = several organs transplanted in the same operation; Old Transplants = with more than 1 year post transplant; ${ }^{*}$ Chi-square test or Student's t-test between Transplant and All Rehab values; ${ }^{a} \mathrm{p}<0.05,{ }^{b} \mathrm{p}<0.01$; Unplanned Discharges = inpatient stay that lasts 3 days or less, including the admission day; LOS = length of stay; FIM = functional independence measure; FIM gain = difference between discharge FIM and admission FIM scores; FIM efficiency = FIM gain divided by the length of stay. 
Table 4. Demographics and outcomes of organ transplant group by year.

\begin{tabular}{|c|c|c|c|c|c|c|}
\hline & 2004 & 2005 & 2006 & 2007 & 2008 & p Value ${ }^{*}$ \\
\hline Patients (\%) & $9(5.2)$ & $48(27.7)$ & $47(27.2)$ & $61(35.3)$ & $8(4.6)$ & 0.0 .01 \\
\hline Age (years) & $56.4 \pm 6.8$ & $53.8 \pm 12.0$ & $51.9 \pm 12.1$ & $57.7 \pm 12.4$ & $54.6 \pm 10.1$ & 0.145 \\
\hline \multicolumn{7}{|l|}{ Gender } \\
\hline Males (\%) & $8(88.9)$ & $27(56.2)$ & $24(51.1)$ & $35(57.4)$ & $4(50.0)$ & 0.335 \\
\hline Females (\%) & $1(11.1)$ & $21(43.8)$ & $23(48.9)$ & $26(42.6)$ & $4(50.0)$ & 0.335 \\
\hline Waiting for Rehab Admission (Days \pm SD) & $2.4 \pm 1.6$ & $2.8 \pm 3.1$ & $3.5 \pm 3.1$ & $1.6 \pm 1.9$ & $2.5 \pm 1.6$ & 0.007 \\
\hline Unplanned Discharges (\%) & $0(0.0)$ & $2(4.2)$ & $1(2.1)$ & $6(9.8)$ & $0(0.0)$ & 0.472 \\
\hline Acute Care Readmission (\%) & $1(3.0)$ & $11(23.9)$ & $12(26.1)$ & $9(16.4)$ & $0(0.0)$ & 0.785 \\
\hline LOS (Days $\pm \mathrm{SD})$ & $24.7 \pm 11.9$ & $24.2 \pm 16.7$ & $27.8 \pm 18.1$ & $28.1 \pm 21.7$ & $36.8 \pm 24.2$ & 0.477 \\
\hline Motor FIM $^{\mathrm{TM}}$ Gain $( \pm \mathrm{SD})$ & $24.4 \pm 13.7$ & $8.5 \pm 33.8$ & $10.4 \pm 32.4$ & $15.3 \pm 32.3$ & $26.6 \pm 8.9$ & 0.379 \\
\hline Cognitive FIM $^{\mathrm{TM}}$ Gain $( \pm \mathrm{SD})$ & $-3.9 \pm 11.7$ & $-5.7 \pm 14.0$ & $-6.3 \pm 14.0$ & $-4.0 \pm 12.2$ & $0.9 \pm 1.5$ & 0.615 \\
\hline Total FIM ${ }^{\mathrm{TM}}$ Gain $( \pm \mathrm{SD})$ & $20.6 \pm 22.0$ & $2.8 \pm 47.2$ & $4.1 \pm 45.3$ & $11.3 \pm 43.6$ & $27.5 \pm 9.3$ & 0.447 \\
\hline FIM $^{\mathrm{TM}}$ Efficiency (Points/Day \pm SD) & $1.1 \pm 1.0$ & $-1.0 \pm 4.6$ & $-0.4 \pm 4.1$ & $-0.6 \pm 4.1$ & $1.0 \pm 0.5$ & 0.558 \\
\hline Met Rehab Goals (\%) & $8(88.9)$ & $35(72.9)$ & $33(70.2)$ & $45(73.8)$ & $8(100.0)$ & 0.378 \\
\hline Discharge Home (\%) & $8(88.9)$ & $35(72.9)$ & $33(70.2)$ & $45(73.8)$ & $8(100.0)$ & 0.378 \\
\hline
\end{tabular}

*Chi-square test or Student's t-test between Transplant and All Rehab values; Unplanned Discharges = inpatient stay that lasts 3 days or less, including the admission day; LOS = length of stay; FIM = functional independence measure; FIM gain = difference between discharge FIM and admission FIM scores; FIM efficiency = FIM gain divided by the length of stay.

\subsection{Outcomes of the Partnership RH-MOT}

The waiting time from the moment an organ transplant patient was ready for discharge from the MOT and admission to the RH was on average 2.4 days in April 2004, compared to an average of 1.6 days in 2007, representing a $66.7 \%$ reduction of waiting time to be transferred to the alternative level of care (ALC), in this case the RH. This reduction represented that more beds at the MOT were available for new solid organ transplant patients, improving bed utilization at the MOT.

\section{DISCUSSION}

Evaluating the, outcomes of 173 patients over four years in our RH program, we found a number of statistically significant differences between the outcomes of transplant rehab patients and general rehab patients. Transplant rehab patients were younger, had a longer length of stay, decreased FIM $^{\mathrm{TM}}$ efficiency, and reduced FIM $^{\mathrm{TM}}$ gain, compared to general rehab patients. But a higher proportion of transplant patients who were not readmitted to an acute care hospital went back into their home settings, compared to general rehab patients. One could also consider that over half of the total general rehabilitation patients were admitted to the musculoskeletal program. These consisted mostly of postopera- tive total joint arthroplasties who required a short length of stay and had a higher FIM $^{\mathrm{TM}}$ efficiency. However, even including those less complex musculoskeletal patients, the comparable transplant rehab outcomes are acceptable. Patients post-combined transplants had more immediate ( $<3$ days) transfers to an acute hospital, and a higher rate of readmission to an acute hospital after the first 3 days, and patients who received a heart-lung transplant had greater FIM $^{\mathrm{TM}}$ efficiency than the other organ transplant groups. Overall, these results are convincing to demonstrate that an inpatient rehab program, assuming identified achievable rehab goals, can achieve acceptable outcomes in a manner that is as effective and efficient as the other programs in the $\mathrm{RH}$.

There are however very significant differences between transplant rehab patients and other rehab patients in one area - unplanned discharges. Within the first three days, the rate of sending patients back to the acute hospital is almost three times higher in transplant patients. During the rest of their admission, transplant rehab patients were about ten times more likely to be sent to the acute hospital $(19.1 \%)$ than were general rehab patients $(1.9 \%)$. This is comparable to the rates reported elsewhere for transplant rehab (15\% [21]), or even transfer rates for a similar medically fragile and complex rehab group - oncology patients (21\% [58], 35\% [59]). 
The partnership program between the $\mathrm{RH}$ and the MOT was established for two reasons. One was to improve organ transplant patients physical functioning, which is discussed above, and the other reason was regarding the logistics of the health care of these patients.

Regarding logistics, there are clear advantages to sending patients post-transplant to an inpatient rehabilitation program. The efficiency is increased because more beds in the transplant unit are cleared faster to be available for new organ transplant patients. Post-transplant patients no longer recuperate in high-cost transplant program beds in the MOT program (approximately CAN $\$ 700$ per day, not including costs for housekeeping, dietary, allied health services, corporate overhead, lab \& diagnostic testing). The rehabilitation is better in a rehab unit at lower cost (approximately CAN \$594 per day, including direct and indirect costs), because the unit is appropriately staffed for rehab, has appropriate expertise, and has the equipment and space necessary for rehab. The rehab program focuses on maximum efficiency in recovery of function, meeting goals regarding safety, activities of daily living (both basic and instrumental), mobility, strength, endurance etc. The RH-MOT program has been a success in logistics, in helping patients to move along the continuum of care while remaining in the setting most appropriate to their needs at any given moment.

Therefore, there exists a patient group (post-operative organ transplants) for whom the acute hospital does not meet their needs well. There exist rehabilitation programs which can improve their impairments efficiently and cost effectively. Why do most transplant patients stay in acute hospital beds until discharge, following which some outpatient rehabilitation may or may not be instituted? There are a number of possible reasons. One might be that inpatient rehabilitation is just not part of the culture of the transplant team. This was answered by our partnership process, because the signed agreement served as an indicator of a cultural change, and focussed the communication strategy RH-MOT. A second reason might be that rehabilitation facilities are not comfortable with the complexity and possible instability of these patients and just do not routinely accept them. Again, the RH-MOT partnership was the answer to this. The MOT promised to maintain their medical accountability for these patients during complications, and they did in fact readmit sick patients as needed. A third reason might be that the rehab hospital might feel that they are unfamiliar with transplant impairments and treatment programs for them. With our partnership, the RH developed a formal program, and has acquired considerable expertise. It turns out that most of the impairments are not specific to the transplant patients. Nevertheless, this is now a high profile program for the RH. A fourth reason might be that the costs of converting RH beds to treat complex transplant patients might increase the costs of running each bed without necessarily having the ability to recoup those costs. This could be a significant disincentive in the Canadian health care system with a government funded hospital global budget model (where hospitals receive a fixed amount of money for operating costs, based upon historic experience [60]), in particular the pharmacy budget would suffer a major impact. This would be a weaker disincentive in a case-costing funding model where a fee-for-service payment is billed to payers by the institutions [60]. A fifth reason might be that the initial barriers for the RH to overcome are large, and the initial cost of entry is high-essential factors include a minimum volume of cohorted patients, a team with identified members who acquire expertise, and aggressive RH medical treatment partnered with a full Transplant service backup - a large investment for the RH.

The last reason is that there may have been insufficient published literature to date to persuasively demonstrate that a rehab program will accomplish valued outcomes. Our data supports the pre-existing publications, and convincingly shows that transplant patients, regardless of organ group, improve their function at a rate and to an extent similar to other complex rehabilitation patient groups.

\section{Study Limitations}

While our results are substantial, one should consider the following: this is a retrospective study, which limits certain aspects of information gathering like patients' data, which depends on the accuracy of electronic data entry and the correct rehabilitation patient group (RPG) coding of these inpatients as organ transplant patients. Notably, the current study was conducted in Canada's only dedicated organ transplant rehabilitation program. Consequently, these results may not be representative of the general organ transplant population.

\section{CONCLUSIONS}

A written partnership agreement between a high volume multi-organ transplant service and a specialized rehabilitation hospital produced a program that over four years cleared 173 acute transplant beds expeditiously. The transplant patients had a significantly longer length of stay, decreased FIM $^{\mathrm{TM}}$ efficiency, larger FIM ${ }^{\mathrm{TM}}$ gain, and a higher proportion of them went back into their home settings, compared to general rehabilitation patients. Although statistically significant, these results were not clinically significant because they all remain within the expected range of outcomes that would justify a course of rehabilitation. The rehab program improved patient function (as measured by FIM $^{\mathrm{TM}}$ efficiency) at an 
acceptable rate (1.1 vs. 1.4) compared to the general rehabilitation population in the same rehabilitation hospital (of whom close to half were short stay orthopaedic patients). It is known that for medically very complex patients (e.g., oncology patients), there will be a high rate of transfer back to acute hospital for treatment of complications and intercurrent illness, and this is as true for organ transplant patients in our study. There were greater outcome improvements in organ transplant patients during the last two years of the study (2007 and 2008).

We are planning to conduct a larger retrospective study where we will compare the functional outcomes of patients admitted to the RH organ transplant program with those of organ transplant patients who are not admitted to the RH program, matched by age, gender, and severity of physical function measured by the $\mathrm{FIM}^{\mathrm{TM}}$ ratings. We will also stratify the patients in three comparison groups: the organ transplants, the orthopaedic patients, and the other groups in rehab. In addition, we will compare the rehabilitation outcomes of transplant patients by the organ transplanted to determine if their outcomes are the same or different.

\section{ACKNOWLEDGEMENTS}

The contribution of Arash Kashfi MD in assisting with the statistical analysis is gratefully acknowledged.

\section{REFERENCES}

[1] Bravata, D.M., Olkin, I., Barnato, A.E., Keeffe, E.B. and Owens, D.K. (1999) Health-related quality of life after liver transplantation: A meta-analysis. Liver Transplantation and Surgery, 5, 318-331. http://dx.doi.org/10.1002/lt.500050404

[2] Hathaway, D.K., Winsett, R.P., Johnson, C., Tolley, E.A., Hartwig, M., Milstead, J., et al. (1998) Post kidney transplant quality of life prediction models. Clinical Transplantation, 12, 168-174.

[3] Liem, Y.S., Bosch, J.L., Arends, L.R., Heijenbrok Kal, M.H. and Hunink, M. (2007) Quality of life assessed with the medical outcomes study short form 36 item health survey of patients on renal replacement therapy: A systematic review and meta analysis. Value in Health, 10, 390397. http://dx.doi.org/10.1111/j.1524-4733.2007.00193.x

[4] Smith, G.C., Trauer, T., Kerr, P.G. and Chadban, S.J. (2010) Prospective quality-of-life monitoring of simultaneous pancreas and kidney transplant recipients using the 36-item short form health survey. American Journal of Kidney Diseases, 55, 698-707. http://dx.doi.org/10.1053/j.ajkd.2009.12.025

[5] Isla Pera, P., Moncho Vasallo, J., Torras Rabasa, A., Oppenheimer Salinas, F., Fernandez Cruz Perez, L. and Ricart Brulles, M.J. (2009) Quality of life in simultaneous pancreas-kidney transplant recipients. Clinical Transplantation, 23, 600-605.

http://dx.doi.org/10.1111/j.1399-0012.2009.01054.x
[6] Hummel, M., Michauk, I., Hetzer, R. and Fuhrmann, B. (2001) Quality of life after heart and heart-lung transplantation. Transplantation Proceedings, 33, 3546-3548. http://dx.doi.org/10.1016/S0041-1345(01)02427-7

[7] Littlefield, C., Abbey, S., Fiducia, D., Cardella, C., Greig, P., Levy, G., et al. (1996) Quality of life following transplantation of the heart, liver, and lungs. General Hospital Psychiatry, 18, 36S-47S. http://dx.doi.org/10.1016/S0163-8343(96)00082-5

[8] Pinson, C.W., Feurer, I.D., Payne, J.L., Wise, P.E., Shockley, S. and Speroff, T. (2000) Health-related quality of life after different types of solid organ transplantation. Annals of Surgery, 232, 597-607.

http://dx.doi.org/10.1097/00000658-200010000-00015

[9] Beyer, N., Aadahl, M., Strange, B., Kirkegaard, P., Hansen, B.A., Mohr, T., et al. (1999) Improved physical performance after orthotopic liver transplantation. Liver Transplantation and Surgery, 5, 301-309. http://dx.doi.org/10.1002/lt.500050406

[10] Wickerson, L., Mathur, S. and Brooks, D. (2010) Exercise training after lung transplantation: A systematic review. The Journal of Heart and Lung Transplantation, 29, 497-503. http://dx.doi.org/10.1016/j.healun.2009.12.008

[11] Gordon, E.J., Prohaska, T., Siminoff, L.A., Minich, P.J. and Sehgal, A.R. (2005) Needed: Tailored exercise regimens for kidney transplant recipients. American Journal of Kidney Diseases, 45, 769-774. http://dx.doi.org/10.1053/j.ajkd.2005.01.002

[12] Painter, P.L., Hector, L., Ray, K., Lynes, L., Dibble, S., Paul, S.M., et al. (2002) A randomized trial of exercise training after renal transplantation. Transplantation, 74, 42-48. http://dx.doi.org/10.1097/00007890-200207150-00008

[13] Di Landro, D., Koenigsrainer, A., Oefner, D., Aichberger, C., Romagnoli, G.F. and Margreiter, R. (1996) Experience with 100 combined pancreatic renal transplantations in a single center. Nephron, 72, 547-551. http://dx.doi.org/10.1159/000188937

[14] Haykowsky, M., Taylor, D., Kim, D. and Tymchak, W. (2009) Exercise training improves aerobic capacity and skeletal muscle function in heart transplant recipients. American Journal of Transplantation, 9, 734-739. http://dx.doi.org/10.1111/j.1600-6143.2008.02531.x

[15] Kobashigawa, J.A., Leaf, D.A., Lee, N., Gleeson, M.P., Liu, H., Hamilton, M.A., et al. (1999) A controlled trial of exercise rehabilitation after heart transplantation. New England Journal of Medicine, 340, 272-277. http://dx.doi.org/10.1056/NEJM199901283400404

[16] Stewart, K.J., Badenhop, D., Brubaker, P.H., Keteyian, S.J. and King, M. (2003) Cardiac rehabilitation following percutaneous revascularization, heart transplant, heart valve surgery, and for chronic heart failure. Chest, 123, 21042111. http://dx.doi.org/10.1378/chest.123.6.2104

[17] Stewart, K.J., Badenhop, D., Brubaker, P.H., Keteyian, S.J. and King, M. (2003) Cardiac rehabilitation following percutaneous revascularization, heart transplant, heart valve surgery, and for chronic heart failure. Chest, 123, 2104. http://dx.doi.org/10.1378/chest.123.6.2104

[18] Taylor, R.S., Brown, A., Ebrahim, S., Jolliffe, J., Noorani, 
H., Rees, K., et al. (2004) Exercise-based rehabilitation for patients with coronary heart disease: Systematic review and meta-analysis of randomized controlled trials. The American Journal of Medicine, 116, 682-692. http://dx.doi.org/10.1016/j.amimed.2004.01.009

[19] Tuel, S.M., Meythaler, J.M. and Cross, L.L. (1991) Inpatient comprehensive rehabilitation after liver transplantation. American Journal of Physical Medicine \& Rehabilitation, 70, 242-245.

http://dx.doi.org/10.1097/00002060-199110000-00003

[20] Hastings, J., Gowans, S. and Watson, D.E. (2004) Effectiveness of occupational therapy following organ transplantation. Canadian Journal of Occupational Therapy, 71, 238-242. http://dx.doi.org/10.1177/000841740407100409

[21] Cortazzo, M.H., Helkowski, W., Pippin, B., Boninger, M.L. and Zafonte, R. (2005) Acute inpatient rehabilitation of 55 patients after liver transplantation. American Journal of Physical Medicine \& Rehabilitation, 84, 880884.

http://dx.doi.org/10.1097/01.phm.0000184093.53032.ed

[22] Joshi, A. and Kevorkian, C.G. (1997) Rehabilitation after cardiac transplantation: Case series and literature review. American Journal of Physical Medicine \& Rehabilitation, 76, 249.

http://dx.doi.org/10.1097/00002060-199705000-00019

[23] Cowen, T.D., Huang, C.T., Lebow, J., Devivo, M.J. and Hawkins, L.V.N. (1995) Functional outcomes after inpatient rehabilitation of patients with end-stage renal disease. Archives of Physical Medicine and Rehabilitation, 76, 355-359.

http://dx.doi.org/10.1016/S0003-9993(95)80661-X

[24] Stephenson, A.L., Yoshida, E.M., Abboud, R.T., Fradet, G. and Levy, R.D. (2001) Impaired exercise performance after successful liver transplantation. Transplantation, 72, 1161-1164.

http://dx.doi.org/10.1097/00007890-200109270-00032

[25] Hasse, J.M. (2001) Nutrition assessment and support of organ transplant recipients. Journal of Parenteral and Enteral Nutrition, 25, 120-131. http://dx.doi.org/10.1177/0148607101025003120

[26] Dittmer, D.K. and Teasell, R. (1993) Complications of immobilization and bed rest. Part 1: Musculoskeletal and cardiovascular complications. Canadian Family Physician, 39, 1428-1432, 1435-1437.

[27] Teasell, R. and Dittmer, D.K. (1993) Complications of immobilization and bed rest. Part 2: Other complications. Canadian Family Physician, 39, 1440-1442, 1445-1446.

[28] Koch, S., Spuler, S., Deja, M., Bierbrauer, J., Dimroth, A., Behse, F., et al. (2011) Critical illness myopathy is frequent: Accompanying neuropathy protracts ICU discharge. Journal of Neurology, Neurosurgery \& Psychiatry, 82, 287-293. http://dx.doi.org/10.1136/jnnp.2009.192997

[29] Hudson, L.D. and Lee, C.M. (2003) Neuromuscular sequelae of critical illness. New England Journal of Medicine, 348, 745-747. http://dx.doi.org/10.1056/NEJMe020180

[30] Herridge, M.S., Cheung, A.M., Tansey, C.M., MatteMartyn, A., Diaz-Granados, N., Al-Saidi, F., et al. (2003)
One-year outcomes in survivors of the acute respiratory distress syndrome. New England Journal of Medicine, 348, 683-693. http://dx.doi.org/10.1056/NEJMoa022450

[31] Latronico, N. and Guarneri, B. (2008) Critical illness myopathy and neuropathy. Minerva Anestesiologica, 74, 319-323.

[32] Campellone, J.V., Lacomis, D., Giuliani, M.J. and Kramer, D.J. (1998) Mononeuropathies associated with liver transplantation. Muscle \& Nerve, 21, 896-901. http://dx.doi.org/10.1002/(SICI)1097-4598(199807)21:7< 896::AID-MUS7>3.0.CO;2-1

[33] Campellone, J.V., Lacomis, D., Kramer, D.J., Van Cott, A.C. and Giuliani, M.J. (1998) Acute myopathy after liver transplantation. Neurology, 50, 46-53. http://dx.doi.org/10.1212/WNL.50.1.46

[34] Hockerstedt, K., Kajaste, S., Muuronen, A., Raininko, R., Seppalainen, A.M. and Hillbom, M. (1992) Encephalopathy and neuropathy in end-stage liver disease before and after liver transplantation. Journal of Hepatology, 16, 31-37. http://dx.doi.org/10.1016/S0168-8278(05)80091-1

[35] Ahonen, R.E. (1981) Peripheral neuropathy in uremic patients and in renal transplant recipients. Acta Neuropathologica, 54, 43-53.

http://dx.doi.org/10.1007/BF00691331

[36] Ducloux, D., Schuller, V., Bresson-Vautrin, C. and Chalopin, J.M. (1997) Colchicine myopathy in renal transplant recipients on cyclosporin. Nephrology Dialysis Transplantation, 12, 2389-2392. http://dx.doi.org/10.1093/ndt/12.11.2389

[37] Pantiga, C., Rodrigo, L.R., Cuesta, M., Lopez, L. and Arias, J.L. (2003) Cognitive deficits in patients with hepatic cirrhosis and in liver transplant recipients. The Journal of Neuropsychiatry and Clinical Neurosciences, 15, 84-89. http://dx.doi.org/10.1176/appi.neuropsych.15.1.84

[38] Cupples, S.A. and Stilley, C.S. (2005) Cognitive function in adult cardiothoracic transplant candidates and recipeents. Journal of Cardiovascular Nursing, 20, S74-S87. http://dx.doi.org/10.1097/00005082-200509001-00009

[39] Brown, E.S. (2003) Management of psychiatric side effects associated with corticosteroids. Expert Review of Neurotherapeutics, 3, 69-75. http://dx.doi.org/10.1586/14737175.3.1.69

[40] Newman, M.F., Kirchner, J.L., Phillips-Bute, B., Gaver, V., Grocott, H., Jones, R.H., et al. (2001) Longitudinal assessment of neurocognitive function after coronary-artery bypass surgery. The New England Journal of Medicine, 344, 395-402. http://dx.doi.org/10.1056/NEJM200102083440601

[41] Granger, C.V. and Hamilton, B.B. (1992) The uniform data system for medical rehabilitation report of first admissions for 1990. American Journal of Physical Medicine \& Rehabilitation, 71, 108-113. http://dx.doi.org/10.1097/00002060-199204000-00009

[42] Heinemann, A.W., Kirk, P., Hastie, B.A., Semik, P., Hamilton, B.B., Linacre, J.M., Wright, B.D. and Granger, C. (1997) Relationships between disability measures and nursing effort during medical rehabilitation for patients with traumatic brain and spinal cord injury. Archives of Physical Medicine and Rehabilitation, 78, 143-149. 
http://dx.doi.org/10.1016/S0003-9993(97)90255-0

[43] Oczkowski, W.J. and Barreca, S. (1993) The functional independence measure: Its use to identify rehabilitation needs in stroke survivors. Archives of Physical Medicine and Rehabilitation, 74, 1291-1294. http://dx.doi.org/10.1016/0003-9993(93)90081-K

[44] Pollack, N., Rheault, W. and Stoecker, J.L. (1996) Reliability and validity of the FIM for persons aged 80 years band above from a multilevel continuing care retirement community. Archives of Physical Medicine and Rehabilitation, 77, 1056-1061. http://dx.doi.org/10.1016/S0003-9993(96)90068-4

[45] Segal, M.E., Gillard, M. and Schall, R.R. (1996) Telephone and in-person agreement between stroke patients and caregivers for the functional independence measure. American Journal of Physical Medicine \& Rehabilitation, 75, 208-212. http://dx.doi.org/10.1097/00002060-199605000-00013

[46] Whitlock, J.A. and Hamilton, B.B. (1995) Functional outcome after rehabilitation for severe traumatic brain injury. Archives of Physical Medicine and Rehabilitation, 76, 1103-1112.

http://dx.doi.org/10.1016/S0003-9993(95)80117-0

[47] Heinemann, A.W., Linacre, J.M., Wright, B.D., Hamilton, B.B. and Granger, C.V. (1993) Relationships between impairment and physical disability as measured by the functional independence measure. Archives of Physical Medicine and Rehabilitation, 74, 566-573.

[48] Mokler, P.J., Sandstrom, R., Griffin, M., Farris, L. and Jones, C. (2000) Predicting discharge destination for patients with severe motor stroke: Important functional tasks. Neurorehabilitation and Neural Repair, 14, 181185.

[49] D’Aquila, M.A., Smith, T., Organ, D., Lichtman, S. and Reding, M. (2004) Validation of a lateropulsion scale for patients recovering from stroke. Clinical Rehabilitation, 18, 102-109. http://dx.doi.org/10.1191/0269215504cr709oa

[50] Ring, H., Bar, L. and Abboud, S. (1999) Functional correlates with left-right asymmetry of visual evoked potentials in stroke patients: Modeling and experimental results. Archives of Physical Medicine and Rehabilitation, 80, 166172. http://dx.doi.org/10.1016/S0003-9993(99)90115-6

[51] Saboe, L.A., Darrah, J.M., Pains, K.S. and Guthrie, J. (1997) Early predictors of functional independence 2 years after spinal cord injury. Archives of Physical Medicine and
Rehabilitation, 78, 644-650. http://dx.doi.org/10.1016/S0003-9993(97)90431-7

[52] Mylotte, J.M., Graham, R., Kahler, L., Young, L. and Goodnough, S. (2001) Impact of nosocomial infection on length of stay and functional improvement among patients admitted to an acute rehabilitation unit. Infection Control and Hospital Epidemiology, 22, 83-87. http://dx.doi.org/10.1086/501868

[53] Nakamura, D.Y., Esselman, P.C., Mann, R. and Engrav, L.H. (1997) The inadequacy of the FIM (Functional independence measure) for burns. Journal of Burn Care \& Rehabilitation, 18, S140.

[54] Esselman, P.C., Engrav, L.H., Ptacek, J.T., Kowalske, K. and Krabak, B. (2000) Outcome of burn injuries in older adults. Journal of Burn Care \& Rehabilitation, 21, S192. http://dx.doi.org/10.1097/00004630-200001001-00116

[55] Costa, B.A., Engrav, L.H., Holavanahalli, R., Lezotte, D.C., Patterson, D.R., Kowalske, K.J. and Esselman, P.C. (2003) Impairment after burns: A two-center, prospective report. Burns, 29, 671-675. http://dx.doi.org/10.1016/S0305-4179(03)00153-0

[56] Dodds, T.A., Martin, D.P., Stolov, W.C. and Deyo, R.A. (1993) A validation of the functional independence measurement and its performance among rehabilitation inpatients. Archives of Physical Medicine and Rehabilitation, 74, 531-536. http://dx.doi.org/10.1016/0003-9993(93)90119-U

[57] Ottenbacher, K.J., Smith, P.M., Illig, S.B., Linn, R.T., Ostir, G.V. and Granger, C.V. (2004) Trends in length of stay, living setting, functional outcome, and mortality following medical rehabilitation. JAMA, 292, 1687-1695. http://dx.doi.org/10.1001/jama.292.14.1687

[58] Alam, E., Wilson, R.D. and Vargo, M.M. (2008) Inpatient cancer rehabilitation: A retrospective comparison of transfer back to acute care between patients with neoplasm and other rehabilitation patients. Archives of Physical Medicine and Rehabilitation, 89, 1284-1289. http://dx.doi.org/10.1016/j.apmr.2008.01.014

[59] Guo, Y., Persyn, L., Palmer, J.L. and Bruera, E. (2008) Incidence of and risk factors for transferring cancer patients from rehabilitation to acute care units. American Journal of Physical Medicine \& Rehabilitation, 87, 647-653. http://dx.doi.org/10.1097/PHM.0b013e31817fb94e

[60] Herridge, M.S. (2009) Building consensus on ICU-acquired weakness. Intensive Care Medicine, 35, 1-3. http://dx.doi.org/10.1007/s00134-008-1305-3 


\section{LIST OF ABBREVIATIONS}

QoL $=$ Quality of Life

$\mathrm{ESRD}=$ End-Stage Renal Disease

$\mathrm{FIM}^{\mathrm{TM}}=$ Functional Independence Measure

ICU $=$ Intensive Care Unit

$\mathrm{RH}=$ Rehabilitation Hospital

MOT = Multi-Organ Transplant program

ALC $=$ Alternative Level of Care

CAN\$ $=$ Canadian Dollar

RPG $=$ Rehabilitation Patient Group 